\title{
The chemotherapeutic agent bortezomib induces the formation of stress granules
}

\author{
Marie-Josée Fournier1,2, Cristina Gareau ${ }^{1,2}$ and Rachid Mazroui*1,2
}

\begin{abstract}
Background: Cytoplasmic stress granules (SGs) are specialized storage sites of untranslated mRNAs whose formation occurs under different stress conditions and is often associated with cell survival. SGs-inducing stresses include radiations, hypoxia, viral infections, and chemical inhibitors of specific translation initiation factors. The FDA-approved drug bortezomib (Velcade ${ }^{\circ}$ ) is a peptide boronate inhibitor of the 265 proteasome that is very efficient for the treatment of myelomas and other hematological tumors. Solid tumors are largely refractory to bortezomib. In the present study, we investigated the formation of SGs following bortezomib treatment.

Results: We show that bortezomib efficiently induces the formation of SGs in cancer cells. This process involves the phosphorylation of translation initiation factor elF2a by heme-regulated inhibitor kinase (HRI). Depletion of HRI prevents bortezomib-induced formation of SGs and promotes apoptosis.

Conclusions: This is the first study describing the formation of SGs by a chemotherapeutic compound. We speculate that the activation of $\mathrm{HRI}$ and the formation of SGs might constitute a mechanism by which cancer cells resist bortezomib-mediated apoptosis.
\end{abstract}

\section{Background}

The proteasome is a large multi-subunit complex responsible for the degradation of various proteins, including cell cycle regulators and apoptotic factors, by ubiquitindependent and -independent mechanisms [1,2]. Proteasome inhibitors are known to induce apoptosis in proliferating cells [3-6]. The proteasome inhibitor bortezomib is now FDA-approved and in clinical use against mantle cell myeloma and multiple myeloma, against which it displays strong anti-tumor activity [7-14]. However, solid tumors of various histological origins are refractory to bortezomib treatment, and this resistance is also observed in cancer cell lines derived from solid tumors in vitro [7,15-17]. The mechanisms by which cancer cells resist bortezomib are still largely unknown, although that this resistance is thought to involve the activation of a general stress response [7,15-17].

When exposed to environmental stress, cells rapidly activate pathways generating a coordinated response involving mRNA translation and turnover, that confers

\footnotetext{
* Correspondence: rachid.mazroui@crsfa.ulaval.ca

${ }^{1}$ Centre de recherche de l'hôpital St-François d'Assise (CHUQ/CRSFA), 10 rue de I'Espinay, Quebec, QC G1L 3L5, Canada

Full list of author information is available at the end of the article
}

protection against stress-induced damage and promotes their survival. Noxious conditions (e.g. heat shock, oxidative stress, UV radiations, viral infections, etc.) induce cellular arrest of translation initiation [18]. This translational block is largely due to phosphorylation of translation initiation factor eIF2 $\alpha$ [19]. Under normal growth conditions, eIF2 associates with initiator Met-tRNA ${ }_{i}{ }^{M e t}$ (aminoacylated initiator methionyl-tRNA) and GTP, and participates in the ribosomal selection of the start codon. As a prelude to the joining of the small and large ribosomal subunits, GTP complexed with eIF2 is hydrolysed to GDP, and eIF2-GDP is released from the translational machinery. The GDP-bound eIF2 is recycled to the active eIF2-GTP by a reaction catalyzed by the guanine nucleotide-exchange factor, eIF2B. Stress-induced phosphorylation of eIF2a at Ser51 changes this translation factor from a substrate to an inhibitor of eIF2B. Since intracellular levels of eIF2B are approximately $10-20 \%$ of those of eIF2 in the cytoplasm, phosphorylation of as little as $10 \%$ of eIF2a can be sufficient to sequester virtually all the available eIF2B, thereby blocking the nucleotide exchange activity of eIF2B and therefore inhibiting protein synthesis $[20,21]$. In metazoans, eIF2a is known to be specifically phosphorylated at Ser51 by at least four kinases that 
monitor stress response [18], namely PKR, which is mainly activated by viral infection; protein kinase receptor-like endoplasmic reticulum kinase (PERK), which is activated during endoplasmic reticulum stress; GCN2, a protein monitoring amino acid levels in cells and responding to amino acid deprivation and proteasome inhibition; and heme-regulated inhibitor kinase (HRI), which senses osmotic stress, heat shock and oxidative stress produced by arsenite. Stress-induced phosphorylation of eIF $2 \alpha$ inhibits translation initiation by stalling translation initiation complexes in an inactive form. The accumulation of such stalled complexes is believed to promote the formation of stress granules [22-24].

Stress granules (SGs) are cytoplasmic ribonucleoprotein-containing bodies whose formation is favored by various stress conditions leading to eIF2 $\alpha$ phosphorylation. These include UV irradiation [25], hypoxia [26], arsenite [27-29], and viral infections [30,31]. Since these stress agents are known to inhibit translation initiation, it has been speculated that SGs might represent sites where translation of specific mRNAs is repressed [24]. SGs could repress translation in part by disrupting the interaction of mRNAs with translating ribosomes. A potential role of SGs in translation repression is supported by the observation that specific mRNAs are inefficiently repressed when RNA-binding proteins that contribute to SGs formation are altered [25,28,32-34]. SGs also contain small ribosomal subunits, translation initiation factors and signaling molecules $[23,35]$. Consistent with the proposed role of SGs as temporary storage or triage sites for untranslated mRNAs, large ribosomal subunits are absent from these foci [27]. Once the inducing stress is relieved, SGs gradually disassemble, which allows translation to resume, a condition essential for cell survival. It is thus postulated that the formation of SGs is central to the stress response by contributing to the reprogramming of gene expression which is essential for cell survival [23]. It is however only during the last few years that the pathological importance of SGs formation in cancer cell resistance to apoptosis became apparent. Indeed, the induction of SGs upon exposure to hypoxia [36], or oxidative stress (e.g. arsenite) [37] leads to tumor cell resistance to apoptosis. One underlying mechanism appears to involve the sequestration and inactivation of pro-apoptotic factors in SGs. The formation of SGs induced by hypoxia in cancer cells has been shown to inhibit apoptosis mediated by the anticancer drug etoposide. This effect was attributed to the sequestration of the signaling scaffold protein RACK1 into SGs, thus leading to the suppression of stress-responsive MAP kinase apoptotic pathways [36]. Other mechanisms by which SGs antagonize apoptosis could involve their sequestration of mRNAs encoding key anti-apoptotic factors, thus preventing degradation of the latter [25]. Although SGs have been shown to form following some types of radiotherapy, whether the formation of SGs can be triggered by chemotherapeutic agents such as bortezomib has not been investigated.

We have previously shown that the formation of SGs in response to the proteasome inhibitor MG132 involves phosphorylation of eIF2 $\alpha$ at Ser51 [33]. We found that mouse embryonic fibroblast (MEFs) eIF2 $\alpha^{\mathrm{S} 51 \mathrm{~A}}$, in which eIF2 $\alpha$ Ser51 has been mutated to Ala, fail to form SGs upon MG132 treatment. We had also implicated the GCN2 kinase phosphorylating eIF2 $\alpha$ in the formation of those SGs. We reported that GCN2-/- MEFs cells have decreased phosphorylation of eIF $2 \alpha$ and fail to assemble SGs following MG132 treatment. In the study herein, we now show that bortezomib efficiently induces the formation of SGs in cancer cells. This response involves the phosphorylation of eIF $2 \alpha$ by HRI, as shown by the inhibition of bortezomib-induced SGs upon HRI depletion, which also promotes apoptosis. This is the first study describing the induction of SGs by a chemotherapeutic compound. We speculate that the activation of HRI and the resulting formation of SGs might constitute a mechanism by which cancer cells resist bortezomib-mediated apoptosis.

\section{Results}

\section{Bortezomib induces the formation of SGs in cancer cells}

We first assessed whether proteasome inhibition by bortezomib could induce the formation of SGs. Indeed, bortezomib $(1 \mu \mathrm{M}, 3 \mathrm{~h})$ efficiently induced SGs in HeLa cells, as assessed by immunofluorescence using various SG markers, namely fragile $\times$ mental retardation protein (FMRP), RasGAP-associated endoribonuclease (G3BP), the RNA-binding protein HuR, eIF4E, and fragile $\times$ mental retardation syndrome-related protein 1 (FXR1) (Fig. $1 \mathrm{~A}$ and 1E). Similar results were obtained using other cancer cells such as Calu-I (lung cancer) and Caco (colon cancer) cells (see below and data not shown). In contrast, Hs578T breast cancer cells failed to form SGs in response to bortezomib (see below). Thus, the formation of SGs upon bortezomib treatment is not restricted to HeLa cells and does not occur in all cancer cells. As expected, the formation of SGs in HeLa cells correlated with a reduction of global translation as measured by metabolic labeling (Fig. 1B) and an induction of eIF2 $\alpha$ phosphorylation (Fig. 1C, top panel). Bortezomib-induced SGs are reversible since they disassemble following prolonged treatment with bortezomib $(1 \mu \mathrm{M}, 10 \mathrm{~h})$ (Fig. 1D-E), allowing a partial recovery of global translation (Fig. 1B). Intriguingly, the disassembly of SGs and the associated translation recovery do not require dephosphorylation of eIF $2 \alpha$ since phosphorylation of this factor remained high after prolonged bortezomib addition (Fig. 1C, top panel). Moreover, this disassembly of SGs was not a consequence 


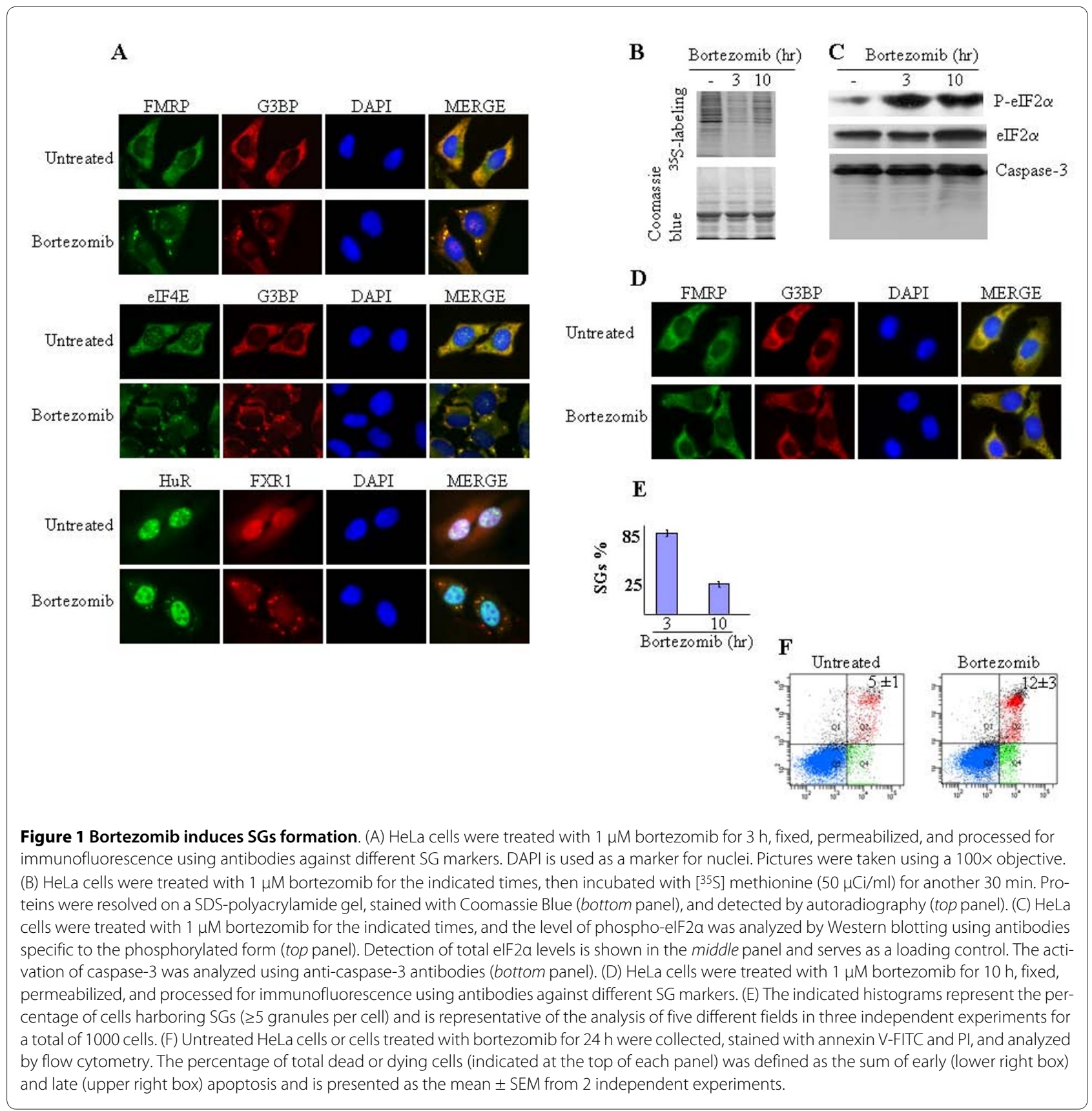

of apoptosis, as assessed by the lack of activation of caspase-3, the main effector of caspase-dependent apoptosis (Fig. 1C, bottom panel), and negative results in the annexin $\mathrm{V}$ staining assay (Fig. 1F). The latter results indicate that HeLa cells are resistant to bortezomib-mediated apoptosis. Overall, our results show that bortezomib induces the formation of SGs.

\section{Depletion of HRI prevents bortezomib-induced SGs}

We have previously implicated the GCN2 kinase as being responsible for eIF $2 \alpha$ phosphorylation in the formation of SGs following MG132 treatment [33]. More recently, it was shown that HRI-/- MEFs cells exhibit altered phosphorylation of eIF $2 \alpha$ in response to both MG132 and bortezomib [38]. Whether HRI, GCN2, or both are responsible for bortezomib-mediated eIF $2 \alpha$ phosphorylation, thus leading to the formation of SGs has not been investigated in cancer cells. To address this question, we first assessed the formation of SGs upon depletion of HRI and GCN2. HeLa cells were treated with specific siRNAs directed against HRI (HRI-1), GCN2 (GCN2-1), or with a control siRNA. Due to the absence of suitable anti-HRI antibodies, we assessed the ability of HRI-1 to knock down its target mRNA using real-time quantitative 
reverse transcription (qRT)-PCR analysis. The results show that HRI-1 efficiently targeted HRI mRNA to degradation (Fig. 2A). GCN2-1 also efficiently depleted GCN2 mRNA as evidenced by (qRT)-PCR (Fig. 2B). The induction of SGs by bortezomid was then assessed by immunofluorescence using specific SGs markers (Fig. $2 \mathrm{C})$. Less than $1 \%$ of cells treated with HRI siRNA displayed SGs in response to bortezomib. In contrast, more than $40 \%$ of GCN2-1-treated cells formed SGs upon bortezomib treatment. Control siRNA had a marginal effect on SGs formation since $>60 \%$ of the cells thus treated formed SGs following bortezomib treatment. These results indicate that HRI depletion prevents the induction of SGs by bortezomib. This effect of HRI deple- tion is likely due to altered eIF2 $\alpha$ phosphorylation as it significantly reduced the extent of eIF $2 \alpha$ phosphorylation induced by bortezomib (Fig. 2D). However, the phosphorylation of eIF2 $\alpha$ was not completely abolished in HRIdepleted cells following bortezomib treatment. This indicates that other kinases might contribute to the phosphorylation of eIF $2 \alpha$ induced by bortezomib, as shown by the slight reduction of that endpoint upon depletion of the GCN2 kinase (Fig. 2D). Our results indicate that under our conditions HRI is the major kinase involved in the phosphorylation of eIF $2 \alpha$ induced by bortezomib, with GCN2 also contributing to this modification. This minimal contribution of GCN2 could explain the residual eIF2 $\alpha$ phosphorylation observed in HRI-depleted cells.
A

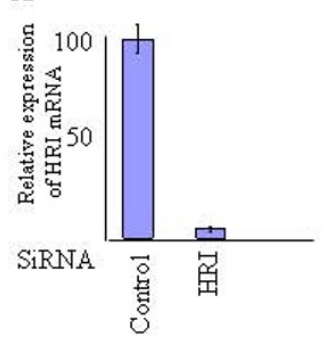

B

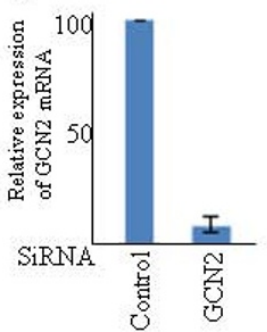

D
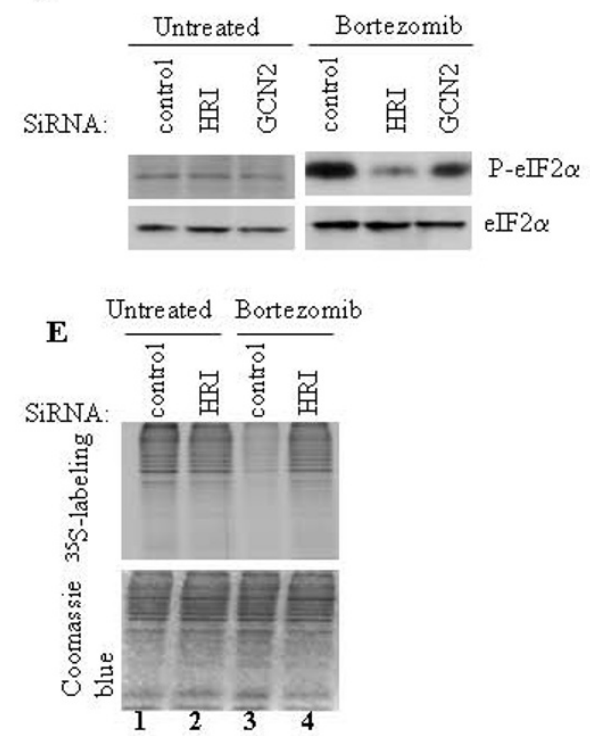

$\mathbf{C}$

Untreated

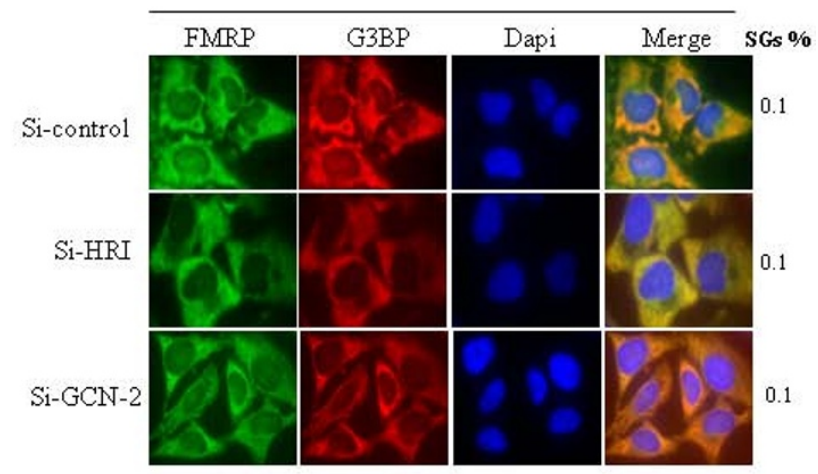

Bortezomib

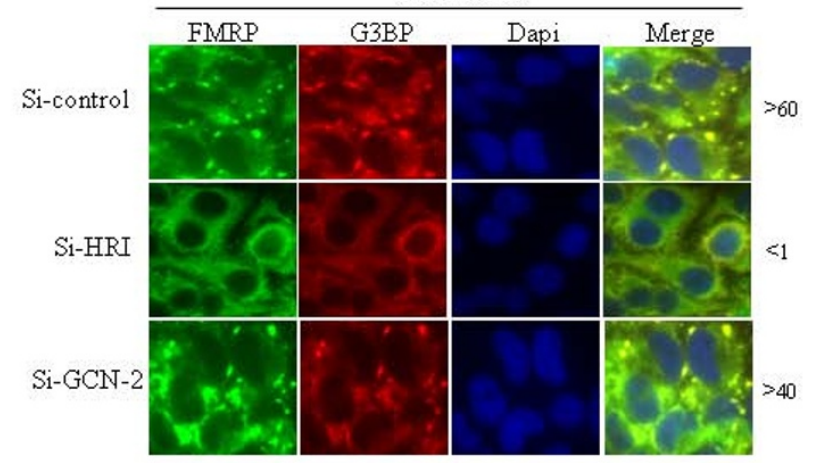

Figure 2 Reducing HRI levels by siRNA prevents bortezomib-induced SGs formation. (A, C) HeLa cells were transfected for $48 \mathrm{~h}$ with anti-HRI (HRI-1) or anti-GCN2 siRNAs (GCN2-1), or with a control siRNA. (A, B) q(RT)-PCR of HRI (A) and GCN-2 mRNAs (B). Transfected cells were collected and their mRNA content was isolated. The amount of HRI and GCN-2 mRNAs relative to GAPDH mRNA was quantified by real-time $q(R T)-P C R$ using the $\triangle \triangle C t$ method. The results are presented as the mean of triplicate measurements, with error bars corresponding to the SEM. (C) Transfected cells were processed for immunofluorescence using antibodies against different SG markers, as above. (D) HeLa cells were transfected for $48 \mathrm{~h}$ with HRI-1, GCN21 , or with a control siRNA, and then treated with bortezomib for $4 \mathrm{~h}$. Cells were collected and protein extracts were analyzed by Western blot analysis for the amount of phospho- and total elF2a as described in Figure 1. (E) HeLa cells were transfected for $48 \mathrm{~h}$ with HRI-1 siRNA or with control siRNA, and then treated with bortezomib for $3 \mathrm{~h}$ before a 30 -min incubation with $[35 \mathrm{~S}]$ methionine $(50 \mu \mathrm{Ci} / \mathrm{ml})$. Proteins were resolved on SDS-polyacrylamide gels, stained with Coomassie Blue (bottom panel), and detected by autoradiography (top panel). 
Residual phosphorylation of eIF2 $\alpha$ in HRI-/- is however insufficient to trigger either the formation of SGs (Fig. $2 \mathrm{C}$ ) or the inhibition of general translation (Fig. 2E). This suggests that a threshold in the extent of eIF $2 \alpha$ phosphorylation might be required to induce SGs upon treatment with bortezomib. Thus, the phosphorylation of eIF $2 \alpha$ seems to be involved in the formation of SGs which is induced by bortezomib. Our data clearly show that this process requires the activity of HRI.

\section{HRI depletion promotes apoptosis following bortezomib treatment}

Previous studies have reported that MEFs lacking HRI fail to form SGs following treatment with arsenite [39]. Quite significantly, HRI deficiency resulted in cell death during the recovery phase from arsenite treatment. Whether HRI can promote resistance of cancer cells to chemotherapeutic agents has not been investigated. We next addressed the hypothesis that HRI depletion might sensitize HeLa cells to bortezomib-mediated apoptosis. To that purpose, HeLa cells treated with either HRI-1 or control siRNAs were exposed to bortezomib for 10 and $24 \mathrm{~h}$, and apoptosis was then assessed by assaying caspase- 3 activation and annexin V staining. Depletion of HRI, which was confirmed by (qRT)-PCR, did not induce significant apoptosis per se (Fig. 3A-B). However, HRI depletion induced apoptosis in a high percentage of cells upon bortezomib treatment (Fig. 3A, B).

To further confirm the role of HRI in promoting resistance of cancer cells to bortezomib-induced apoptosis, we performed clonogenic survival assays. For this, HeLa cells were treated with anti-HRI or control siRNAs, incubated with bortezomib and replated in fresh medium for $10 \mathrm{~d}$, at which point colonies were counted. Depleting HRI significantly decreased cell survival and growth following treatment with bortezomib (Fig. 3C). Overall, the results identified HRI as an SGs-promoting factor that confers resistance to bortezomib-induced apoptosis. Since SGs are known to antagonize apoptosis [24], our results suggest that HRI may promote cancer cell resistance to bortezomib, at least in part, by inducing SGs. One corollary of the latter finding is that cells which fail to form SGs following bortezomib treatment might become more susceptible to apoptosis. We assessed this hypothesis using Hs578T cells, which do not form SGs upon bortezomib treatment (Fig. 4A). HeLa and Calu-I cells were used as positive controls. As shown using caspase- 3 activation and annexin $\mathrm{V}$ staining assays, bortezomib induces a high percentage of apoptosis in Hs578T cells while both HeLa and Calu-I cells are resistant to that treatment (Fig. 4B-C). As expected, bortezomib-mediated apoptosis inhibited Hs578T cell growth after removing the drug, as evidenced by a clonogenic survival assay (Fig. 4D). We obtained similar results using MDA-MB-
231 human breast carcinoma cells which do not form SGs upon bortezomib treatment (data not shown). Thus, for the set of cell lines selected here, the formation of SGs in cancer cells correlates with their resistance to bortezomib.

\section{Discussion}

The present study shows for the first time that bortezomib can induce the reversible formation of SGs in cancer cells. The formation of SGs is associated with a reduction of general mRNA translation, while their disassembly following extended incubation with bortezomib correlates with a partial recovery of general translation. SGs production also correlates with the phosphorylation of eIF2 $\alpha$ by HRI. Depletion of HRI blocks both the formation of SGs and the chemoresistance of cancer cells to bortezomib. Our studies unveil a specific survival pathway that involves HRI and the formation of SGs, which might be targeted to prevent cancer cell resistance to bortezomib-mediated apoptosis.

It is well known that under different stress conditions, eIF2 $\alpha$ phosphorylation triggers SGs formation [23]. Our present work demonstrates that depletion of HRI prevents the formation of SGs and decreases eIF $2 \alpha$ phosphorylation induced upon bortezomib treatment. However, although HRI depletion completely prevents the formation of SGs induced by bortezomib, it leaves a residual but significant amount of eIF $2 \alpha$ phosphorylation unaffected in that model. That residual level of eIF $2 \alpha$ phosphorylation could be due either to an incomplete suppression of HRI protein synthesis, or to the activation of the GCN2 kinase, although we cannot exclude the possible contribution of the other eIF2 $\alpha$ kinases [23]. Notwithstanding these observations, the residual phosphorylation of eIF2 $\alpha$ observed in HRI-depleted cells treated with bortezomib is clearly insufficient for triggering the formation of SGs. One possibility is that initiating the formation of SGs requires a minimum threshold of eIF $2 \alpha$ phosphorylation. Another possibility is that, in the bortezomib model, HRI might promote the formation of SGs via mechanisms other than or in addition to eIF2 $\alpha$ phosphorylation. We and others have described the inactivation of the translation initiation factor eIF4A as an alternative pathway for the induction of SGs which occurs independently of eIF2 $\alpha$ phosphorylation and in absence of any additional stress $[30,40]$. We subsequently found that inactivation of other translation initiation factors also induces the formation of SGs in absence of stress [41]. In this context, it is tempting to speculate that HRI may affect other, as yet unknown translation initiation factors in addition to phosphorylating eIF $2 \alpha$, thus triggering the formation of SGs upon bortezomib treatment. Other pathways whose inactivation impairs the induction of SGs by stress agents also include microtubule polymer- 
A

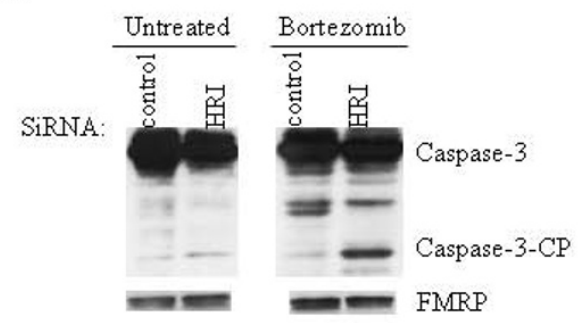

C

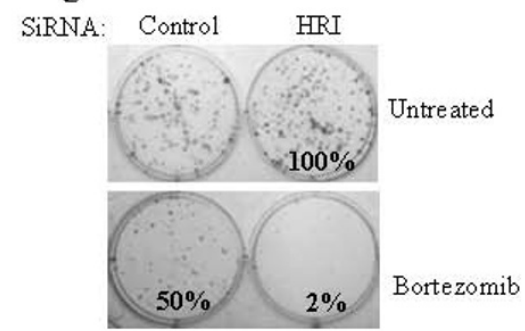

B
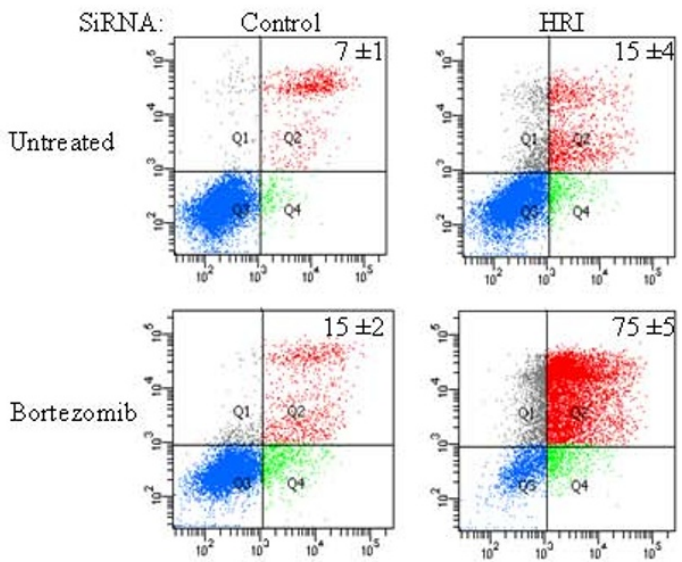

Figure 3 Reducing HRI levels by siRNA promotes bortezomib-mediated apoptosis. (A) HeLa cells were transfected for $48 \mathrm{~h}$ with HRI-1 or control siRNA, treated with bortezomib for $24 \mathrm{~h}$, and total extracted proteins were analyzed by Western blot using anti-caspase-3 antibodies (top panel). CP: cleaved product. FMRP serves as a loading control (bottom panel). (B) Following treatment with HRI-1 or control siRNA, HeLa cells were incubated with bortezomib for $24 \mathrm{~h}$, then stained with annexin V-FITC and Pl, and analyzed by flow cytometry. The percentage of total dead or dying cells (indicated at the top of each panel) was defined as the sum of early (lower right box) and late (upper right box) apoptosis and is presented as the mean \pm SEM from two independent experiments. (C) Following treatment with HRI-1 or control siRNA, HeLa cells were incubated with bortezomib for $24 \mathrm{~h}$, trypsinized, counted, replated in the absence of drug, and incubated for $10 \mathrm{~d}$. Before colony counting, cells were fixed and dried. Populations $>50$ cells were counted as one surviving colony. Data were calculated as the percentage of surviving colonies relative to control (untreated) plates. The results are expressed as the mean of triplicate measurements.

ization and the acetylglucosamination (O-GlcNAc) modification of ribosomal proteins [24]. It will be interesting to investigate the role of these pathways in the formation of SGs and test if HRI depletion could affect those pathways in cells treated with bortezomib.

Previous studies have shown that HRI-deficient MEFs fail to form SGs upon arsenite treatment [39]. This effect of HRI knockout is physiologically relevant since it resulted in massive cell death during the recovery phase from arsenite treatment [39]. However, this model was not investigated in cancer cells, and more importantly, the role of HRI activation in chemoresistance to bortezomib had never been addressed. Our work has thus unveiled a critical role of HRI in promoting cancer cell resistance to bortezomib, at least in part via the induction of SGs. HRI is known to be highly expressed in erythroid cells, although minimal expression of HRI is also found in a wide range of non-erythroid cells $[42,43]$. It is thus intriguing that HRI plays a critical role in promoting resistance of non-erythroid cells such as HeLa to apoptosis. One possibility is that the expression and/or activation of HRI might be altered in cancer cells of nonerythroid origin. Our $\mathrm{q}(\mathrm{RT})-\mathrm{PCR}$ analysis indicates that HRI mRNA is indeed abundant in HeLa cells and its high expression remains unaltered by bortezomib treatment (data not shown). It will be interesting to compare the expression of HRI in bortezomib-resistant and -sensitive cancer cells. The mechanism of HRI activation by borte- 


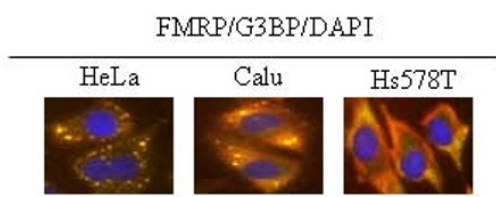

$\mathrm{C}$

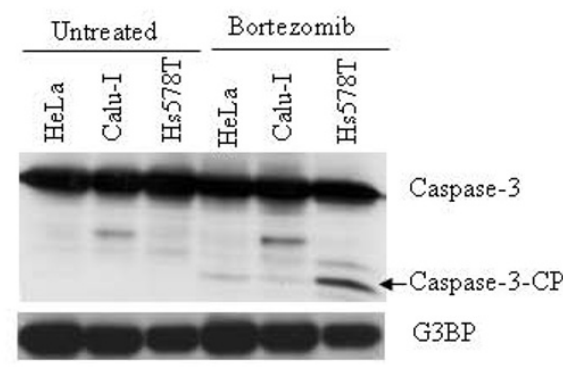

D

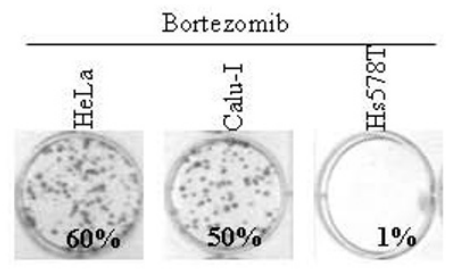

B
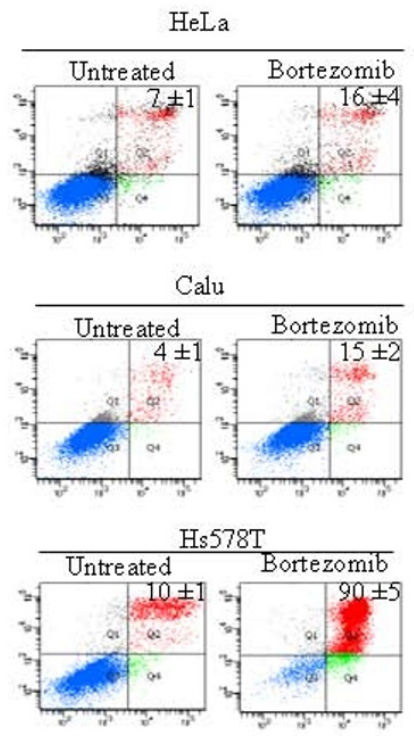

Figure 4 The formation of SGs correlates with resistance to bortezomib-mediated apoptosis. HeLa, Calu-1, and Hs578T cells were treated with bortezomib for $3 \mathrm{~h}$ (A) or $24 \mathrm{~h}$ (B to D). (A) Cells were processed for immunofluorescence to detect SGs using anti-FMRP and anti-G3BP antibodies. (B) Cells were stained with annexin V-FITC and PI, and analyzed by flow cytometry. The percentage of total dead or dying cells (indicated at the top of each panel) was defined as the sum of early (lower right box) and late (upper right box) apoptosis and is presented as the means \pm SEM from two independent experiments. (C) Cells were harvested and protein extracts analyzed by Western blot for the activation of caspase-3 using anti-caspase3 antibodies. G3BP serves as a loading control. (D) Following bortezomib treatment for $24 \mathrm{~h}$, cells were trypsinized, replated in the absence of drug, and incubated for $10 \mathrm{~d}$. Before colony counting, cells were fixed and dried. Populations $>50$ cells were counted as one surviving colony. Data were calculated as the percentage of surviving colonies relative to untreated plates. The results are presented as the mean of triplicate measurements.

zomib is currently unknown but may involve an interaction with heat shock proteins. Hsp70 and Hsp90 are two heat shock proteins which act as molecular chaperones to modify the conformation of other proteins [44]. In reticulocytes, Hsp70 and Hsp90 were shown to activate HRI following arsenite treatment [45]. In addition to their role of chaperones, overexpression of Hsp70 and Hsp90 in cancer cells confers protection against apoptosis. However, depletion of the inducible form of Hsp70 (Hsp72) does not impair the induction of SGs by bortezomib (data not shown), indicating that this protein may not be involved in the activation of HRI under our conditions. The role of Hsp90 in promoting bortezomib-induced HRI activation, and the formation of SGs remains to be investigated.
How could the formation of SGs promote cancer cell resistance to bortezomib-mediated apoptosis? SGs could enhance this survival pathway by sequestering untranslated mRNAs to free the ribosomes needed for the efficient and rapid translation of mRNAs encoding antiapoptotic factors [22]. In addition, SGs might promote tumor cell survival by preventing the degradation of mRNAs encoding key survival proteins, as reported by Moeller et al. [25]. In the latter study, it was shown that radiotherapy induces the formation of SGs where mRNAs encoding anti-apoptotic cytokines such as VEGF are recruited and accumulated. Following reoxygenation, however, SGs disassemble, thus releasing those mRNAs that are then translated in large amounts. The ensuing overproduction of cytokines then causes radioresistance 
of the tumor and its subsequent regrowth. This mechanism could also explain the effects of depleting two SGspromoting factors, TIA and HDAC6, in preventing cell survival. In these studies, depletion of either TIA or HDAC6 was shown to prevent arsenite-induced SGs formation, thus promoting apoptosis during recovery from arsenite treatment $[37,39]$. Other mechanisms by which SGs prevent cancer cell resistance to bortezomib might involve the sequestration and inactivation of key apoptotic signaling molecules such as RACK1 or TRAF2 $[36,46]$, thus preventing the initiation of apoptotic cascades. Clearly, further studies are needed to determine if the formation of SGs is a key pathway leading to chemoresistance to bortezomib.

\section{Conclusions}

The present study has established HRI as a critical factor promoting chemoresistance in vitro. Consideration should be taken about developing compounds to target HRI, which could be combined with bortezomib to treat chemoresistant cancers. We also provide a framework for further documenting the therapeutic relevance of targeting the formation of SGs as a new tool to chemosensitize cancer cells.

\section{Methods}

\section{Cell lines and culture}

HeLa, Calu-1 (lung cancer), and Hs 578T (breast cancer) cells were obtained from the American Type Culture Collection (Manassas, VA). Cells were cultured in DMEM supplemented with $10 \%$ fetal bovine serum, penicillin, and streptomycin. All supplements for cell culture were from Sigma-Aldrich (St. Louis, MO).

\section{Drugs and drug treatments}

Bortezomib was purchased from LC Laboratories and dissolved in DMSO to a $65 \mathrm{mM}$ stock solution, and stored at $-20^{\circ} \mathrm{C}$. Bortezomib treatment was performed when cells had reached $60-80 \%$ confluence.

\section{[35 ]Methionine labeling}

Cells in 6-well plates were labeled for 30 min with $1 \mathrm{ml}$ methionine-free DMEM (Sigma) supplemented with 10\% fetal bovine serum and $50 \mu \mathrm{Ci} / \mathrm{ml}$ of $\left[{ }^{35} \mathrm{~S}\right]$ methionine (Easy Tag, PerkinElmer/NEN Radiochemicals).

\section{Antibodies}

Anti-caspase-3, phospho-specific anti-eIF $2 \alpha$ and the pan anti-eIF2 antibodies were purchased from Cell Signaling Technology (Beverly, MA). Anti-HuR, anti-G3BP, antiFMRP, anti-FXR1, and anti-eIF4E have been previously described $[30,33,41]$.

\section{siRNA transfections}

All siRNAs were purchased from Dharmacon. siRNA transfections were performed in HeLa cells essentially as previously documented [47] using Hiperfect reagent according to the manufacturer's protocol (Qiagen and Dharmacon). Twenty-four hours before transfections, cells were trypsinized and plated to obtain $60-80 \%$ confluence the day after. For a 6-well plate, annealed duplexes were used at a final concentration of $50 \mathrm{nM}$. Forty eight hours post-transfection, cells were either fixed and processed for immunofluorescence or harvested for protein and mRNA extraction.

\section{Fluorescence microscopy}

Immunofluorescence experiments were performed as previously described [29]. Briefly, following fixation and permeabilization, cells were incubated with primary antibodies diluted in $0.1 \%$ Tween-20 in phosphate-buffered saline (PBS) for $1 \mathrm{~h}$ at room temperature. After washing, cells were incubated with goat anti-mouse/rabbit IgG $(\mathrm{H}+\mathrm{L})$ secondary antibodies coupled to Alexa Fluor 488/ 594. Fluorescence was visualized using an Olympus fluorescence microscope equipped with AxioCam HR digital camera and the the Axiovision acquisition software. Images were compiled using Adobe Photoshop (Adobe Systems, Mountain View, CA).

\section{Real-time quantitative RT-PCR}

RT-PCR reactions were performed using the Quantitect Reverse Transcription kit (Qiagen). Each reaction was performed by mixing $2 \mu \mathrm{l}$ of RNA at $500 \mathrm{ng} / \mu \mathrm{l}, 10 \mu \mathrm{l}$ of RNase-free water, $2 \mu \mathrm{l}$ of gDNA Wipeout Buffer $7 \times, 4 \mu \mathrm{l}$ of Quantiscript RT Buffer $5 \times, 1 \mu$ l of RT Primer Mix and $1 \mu \mathrm{l}$ of Quantiscript Reverse Transcriptase.

Real-time PCR reactions were carried out using the Power SYBR Green PCR Master mix (Applied Biosystems) in a total volume of $25 \mu \mathrm{l}: 12.5 \mu \mathrm{l}$ of PCR Master Mix, $0.67 \mu \mathrm{l}$ of forward primer at $3.75 \mu \mathrm{M}, 0.67 \mu \mathrm{l}$ of reverse primer at $3.75 \mu \mathrm{M}, 9.2 \mu \mathrm{l}$ of deionized water and 2 $\mu \mathrm{l}$ of RT-PCR. Reactions were run and data analyzed on the MX3000 QRT PCR system (Applied Biosystems) with a 4-stage program: first stage: 2 -min incubation at $50^{\circ} \mathrm{C}$; second stage: $10-\mathrm{min}$ incubation at $95^{\circ} \mathrm{C}$, followed by a 2 step reaction in the third stage: $95^{\circ} \mathrm{C} \times 15 \mathrm{~s}$ and $55^{\circ} \mathrm{C} \times 60$ $\mathrm{s}$ for 40 cycles; and a fourth stage made of a 3-step reaction $\left(95^{\circ} \mathrm{C} \times 15 \mathrm{~s}, 60^{\circ} \mathrm{C} \times 20 \mathrm{~s}\right.$ and $\left.95^{\circ} \mathrm{C} \times 15 \mathrm{~s}\right)$.

For preparing templates for the HRI mRNA, the oligonucleotide pairs used were: 5'-GCCCTGATCAGCCAAGTAAAA-3' (forward primer), and 5'-TCTGGACGAG TATGTGTTGGTG-3' (reverse primer). For preparing templates for the GCN2 mRNA, the oligonucleotide pairs used were: 5'-CAAGGCCTAACTGGTGAAGA-3' (forward primer), and 5'-AGGTAGGTGGGCATTTAACC-3' (reverse primer). For preparing templates for the glyceraldehyde 3-phosphate dehydrogenase (GAPDH) mRNA, the oligonucleotide pairs used were: 5'-ACGACCACTTTGTCAAGCTC-3' (forward primer), and 5'-GTTG CTGTAGCCAAATTCGT-3' (reverse primer). 


\section{Annexin V-fluorescein isothiocyanate/propidium iodide assay}

Following treatments, both adherent and detached cells were harvested. Cells were washed with ice-cold PBS, then pelleted again at $1500 \mathrm{rpm}$ for $10 \mathrm{~min}$ at $4^{\circ} \mathrm{C}$, and resuspended in ice-cold binding buffer (10 mM HEPES/ $\mathrm{NaOH}, \mathrm{pH} 7.4,140 \mathrm{mM} \mathrm{NaCl}, 2.5 \mathrm{mM} \mathrm{CaCl} 2)$. The cells were subsequently stained with annexin V-fluorescein isothiocyanate (FITC) and propidium iodide (PI) for 15 min in the dark. A total of 50,000 cells were counted, and dead cells were analyzed by flow cytometry.

\section{Clonogenic survival assay and annexin $\mathrm{V}$ analysis}

Cells were plated in duplicate and incubated for $24 \mathrm{~h}$. Following treatments, cells were washed with PBS, trypsinized, counted, replated $(1 \times 103$ cells per well in 6well plates) in the absence of drug, and incubated for 10 d. Before colony counting, cells were washed with PBS, stained with $0.1 \%(\mathrm{w} / \mathrm{v})$ crystal violet in PBS containing $0.0037 \%(\mathrm{v} / \mathrm{v})$ formaldehyde, rinsed with deionized water and dried. Populations $>50$ cells were counted as one surviving colony.

\section{Competing interests}

The authors declare that they have no competing interests.

\section{Authors' contributions}

All authors read and approved the final manuscript. MJF and CG have equally contributed to this work.

\section{Acknowledgements}

We are grateful to Drs. Yves Labelle and Richard Poulin for providing helpful discussions and for editing the manuscript. This work was supported by a grant from the Canadian Institutes of Health Research (MOP-IC093226), an infrastructure grant from the Canada Foundation for Innovation (MOP-GF091050) and a start-up fund from the Centre Hospitalier Universitaire de Québec-Centre de recherche de l'hôpital St-François d'Assise (CHUQ-CRSFA) to RM. RM is the recipient of a Junior 1 Scholarship from the Fonds de Recherche en Santé du Québec (FRSQ).

\section{Author Details}

1Centre de recherche de I'hôpital St-François d'Assise (CHUQ/CRSFA), 10 rue de I'Espinay, Quebec, QC G1L 3L5, Canada and 2Département de biologie médicale, Université Laval, Quebec, Canada

Received: 9 March 2010 Accepted: 29 April 2010

Published: 29 April 2010

\section{References}

1. Adams J: The development of proteasome inhibitors as anticancer drugs. Cancer Cell 2004, 5(5):417-421.

2. Adams J: The proteasome: a suitable antineoplastic target. Nat Rev Cancer 2004, 4(5):349-360.

3. Drexler HC: Activation of the cell death program by inhibition of proteasome function. Proceedings of the National Academy of Sciences of the United States of America 1997, 94(3):855-860.

4. Imajoh-Ohmi S, Kawaguchi T, Sugiyama S, Tanaka K, Omura S, Kikuchi H: Lactacystin, a specific inhibitor of the proteasome, induces apoptosis in human monoblast U937 cells. Biochem Biophys Res Commun 1995, 217(3):1070-1077.

5. Lopes UG, Erhardt P, Yao R, Cooper GM: p53-dependent induction of apoptosis by proteasome inhibitors. The Journal of biological chemistry 1997, 272(20):12893-12896.
6. Sloss CM, Wang F, Liu R, Xia L, Houston M, Ljungman D, Palladino MA, Cusack JC Jr: Proteasome inhibition activates epidermal growth factor receptor (EGFR) and EGFR-independent mitogenic kinase signaling pathways in pancreatic cancer cells. Clin Cancer Res 2008, 14(16):5116-5123.

7. McConkey DJ, Zhu K: Mechanisms of proteasome inhibitor action and resistance in cancer. Drug Resist Updat 2008, 11(4-5):164-179.

8. Richardson PG: A review of the proteasome inhibitor bortezomib in multiple myeloma. Expert opinion on pharmacotherapy 2004, 5(6):1321-1331.

9. Richardson PG, Anderson KC: Bortezomib: a novel therapy approved for multiple myeloma. Clin Adv Hematol Oncol 2003, 1(10):596-600.

10. Richardson PG, Barlogie B, Berenson J, Singhal S, Jagannath S, Irwin D, Rajkumar SV, Srkalovic G, Alsina M, Alexanian R, et al:: A phase 2 study of bortezomib in relapsed, refractory myeloma. The New England journal of medicine 2003, 348(26):2609-2617.

11. Richardson PG, Hideshima T, Anderson KC: Bortezomib (PS-341): a novel, first-in-class proteasome inhibitor for the treatment of multiple myeloma and other cancers. Cancer Control 2003, 10(5):361-369.

12. Richardson PG, Hideshima T, Mitsiades C, Anderson K: Proteasome inhibition in hematologic malignancies. Annals of medicine 2004, 36(4):304-314

13. Richardson PG, Mitsiades C, Schlossman R, Ghobrial I, Hideshima T, Munshi N, Anderson KC: Bortezomib in the front-line treatment of multiple myeloma. Expert Rev Anticancer Ther 2008, 8(7):1053-1072.

14. Sterz J, von Metzler I, Hahne JC, Lamottke B, Rademacher J, Heider U, Terpos E, Sezer O: The potential of proteasome inhibitors in cancer therapy. Expert opinion on investigational drugs 2008, 17(6):879-895.

15. Codony-Servat J, Tapia MA, Bosch M, Oliva C, Domingo-Domenech J, Mellado B, Rolfe M, Ross JS, Gascon P, Rovira A, et al.: Differential cellular and molecular effects of bortezomib, a proteasome inhibitor, in human breast cancer cells. Molecular cancer therapeutics 2006, 5(3):665-675.

16. Rajkumar SV, Richardson PG, Hideshima T, Anderson KC: Proteasome inhibition as a novel therapeutic target in human cancer. $J$ Clin Oncol 2005, 23(3):630-639.

17. Tang ZY, Wu YL, Gao SL, Shen HW: Effects of the proteasome inhibitor bortezomib on gene expression profiles of pancreatic cancer cells. The Journal of surgical research 2008, 145(1):111-123.

18. Wek RC, Jiang HY, Anthony TG: Coping with stress: elF2 kinases and translational control. Biochem Soc Trans 2006, 34(Pt 1):7-11.

19. Holcik M, Sonenberg N: Translational control in stress and apoptosis. Nature reviews 2005, 6(4):318-327.

20. Barber GN: The dsRNA-dependent protein kinase, PKR and cell death. Cell death and differentiation 2005, 12(6):563-570.

21. Lu L, Han AP, Chen JJ: Translation initiation control by heme-regulated eukaryotic initiation factor 2alpha kinase in erythroid cells under cytoplasmic stresses. Molecular and cellular biology 2001, 21(23):7971-7980.

22. Anderson P, Kedersha N: Visibly stressed: the role of elF2, TIA-1, and stress granules in protein translation. Cell Stress Chaperones 2002, 7(2):213-221.

23. Anderson P, Kedersha N: Stress granules: the Tao of RNA triage. Trends in biochemical sciences 2008, 33(3):141-150.

24. Buchan JR, Parker R: Eukaryotic stress granules: the ins and outs of translation. Molecular cell 2009, 36(6):932-941.

25. Moeller BJ, Cao Y, Li CY, Dewhirst MW: Radiation activates HIF-1 to regulate vascular radiosensitivity in tumors: role of reoxygenation, free radicals, and stress granules. Cancer Cell 2004, 5(5):429-441.

26. Gardner LB: Hypoxic inhibition of nonsense-mediated RNA decay regulates gene expression and the integrated stress response. Molecular and cellular biology 2008, 28(11):3729-3741.

27. Kedersha N, Chen S, Gilks N, Li W, Miller IJ, Stahl J, Anderson P: Evidence that ternary complex (elF2-GTP-tRNA(i)(Met))-deficient preinitiation complexes are core constituents of mammalian stress granules. Molecular biology of the cell 2002, 13(1):195-210.

28. Kedersha N, Cho MR, Li W, Yacono PW, Chen S, Gilks N, Golan DE, Anderson P: Dynamic shuttling of TIA-1 accompanies the recruitment of mRNA to mammalian stress granules. J Cell Biol 2000 151(6):1257-1268

29. Mazroui R, Huot ME, Tremblay S, Filion C, Labelle Y, Khandjian EW: Trapping of messenger RNA by Fragile $\times$ Mental Retardation protein 
30. Mazroui R, Sukarieh R, Bordeleau ME, Kaufman RJ, Northcote P, Tanaka J, Gallouzi I, Pelletier J: Inhibition of ribosome recruitment induces stress granule formation independently of eukaryotic initiation factor 2alpha phosphorylation. Molecular biology of the cell 2006, 17(10):4212-4219.

31. Mclnerney GM, Kedersha NL, Kaufman RJ, Anderson P, Liljestrom P: Importance of elF2alpha phosphorylation and stress granule assembly in alphavirus translation regulation. Molecular biology of the cell 2005, 16(8):3753-3763.

32. Gilks N, Kedersha N, Ayodele M, Shen L, Stoecklin G, Dember LM Anderson P: Stress granule assembly is mediated by prion-like aggregation of TIA-1. Molecular biology of the cell 2004 15(12):5383-5398

33. Mazroui R, Di Marco S, Kaufman RJ, Gallouzi IE: Inhibition of the ubiquitin-proteasome system induces stress granule formation. Molecular biology of the cell 2007, 18(7):2603-2618.

34. Tsai NP, Ho PC, Wei LN: Regulation of stress granule dynamics by Grb7 and FAK signalling pathway. The EMBO journal 2008, 27(5):715-726.

35. Anderson P, Kedersha N: RNA granules. J Cell Biol 2006, 172(6):803-808.

36. Arimoto K, Fukuda H, Imajoh-Ohmi S, Saito H, Takekawa M: Formation of stress granules inhibits apoptosis by suppressing stress-responsive MAPK pathways. Nature cell biology 2008.

37. Kwon $S$, Zhang Y, Matthias P: The deacetylase HDAC6 is a novel critical component of stress granules involved in the stress response. Genes \& development 2007, 21(24):3381-3394.

38. Yerlikaya A, Kimball SR, Stanley BA: Phosphorylation of elF2alpha in response to $26 \mathrm{~S}$ proteasome inhibition is mediated by the haemregulated inhibitor (HRI) kinase. The Biochemical journal 2008, 412(3):579-588

39. McEwen E, Kedersha N, Song B, Scheuner D, Gilks N, Han A, Chen رل Anderson P, Kaufman RJ: Heme-regulated inhibitor kinase-mediated phosphorylation of eukaryotic translation initiation factor 2 inhibits translation, induces stress granule formation, and mediates survival upon arsenite exposure. The Journal of biological chemistry 2005, 280(17):16925-16933.

40. Dang Y, Kedersha N, Low WK, Romo D, Gorospe M, Kaufman R, Anderson P, Liu JO: Eukaryotic initiation factor 2alpha-independent pathway of stress granule induction by the natural product pateamine $A$. The Journal of biological chemistry 2006, 281(43):32870-32878

41. Mokas S, Mills JR, Garreau C, Fournier MJ, Robert F, Arya P, Kaufman RJ, Pelletier J, Mazroui R: Uncoupling stress granule assembly and translation initiation inhibition. Molecular biology of the cell 2009, 20(11):2673-2683

42. Berlanga JJ, Herrero S, de Haro C: Characterization of the heminsensitive eukaryotic initiation factor 2alpha kinase from mouse nonerythroid cells. The Journal of biological chemistry 1998, 273(48):32340-32346.

43. Mellor H, Flowers KM, Kimball SR, Jefferson LS: Cloning and characterization of CDNA encoding rat hemin-sensitive initiation factor-2 alpha (elF-2 alpha) kinase. Evidence for multitissue expression. The Journal of biological chemistry 1994, 269(14):10201-10204.

44. Jolly C, Morimoto RI: Role of the heat shock response and molecular chaperones in oncogenesis and cell death. Journal of the National Cancer Institute 2000, 92(19):1564-1572.

45. Lu L, Han AP, Chen JJ: Translation initiation control by heme-regulated eukaryotic initiation factor 2alpha kinase in erythroid cells under cytoplasmic stresses. Molecular and cellular biology 2001 21(23):7971-7980

46. Kim WJ, Back SH, Kim V, Ryu I, Jang SK: Sequestration of TRAF2 into stress granules interrupts tumor necrosis factor signaling under stress conditions. Molecular and cellular biology 2005, 25(6):2450-2462.

47. Mazroui R, Di Marco S, Clair E, von Roretz C, Tenenbaum SA, Keene JD, Saleh M, Gallouzi IE: Caspase-mediated cleavage of HuR in the cytoplasm contributes to pp32/PHAP-I regulation of apoptosis. J Cell Biol 2008, 180(1):113-127.

doi: $10.1186 / 1475-2867-10-12$

Cite this article as: Fournier et al., The chemotherapeutic agent bortezomib induces the formation of stress granules Cancer Cell International 2010, 10:12

\section{Submit your next manuscript to BioMed Central and take full advantage of:}

- Convenient online submission

- Thorough peer review

- No space constraints or color figure charges

- Immediate publication on acceptance

- Inclusion in PubMed, CAS, Scopus and Google Scholar

- Research which is freely available for redistribution

Submit your manuscript at www.biomedcentral.com/submit 